\title{
The transformational potential of Nationally Appropriate Mitigation Actions in Tanzania: assessing the concept's cultural legitimacy among stakeholders in the solar energy sector
}

Latif Amars, Fridahl Mathias, Markus Hagemann, Frauke Röser and Björn-Ola Linnér

\author{
Linköping University Post Print
}

\section{Tweet}

N.B.: When citing this work, cite the original article.

This is an electronic version of an article published in:

Latif Amars, Fridahl Mathias, Markus Hagemann, Frauke Röser and Björn-Ola Linnér, The transformational potential of Nationally Appropriate Mitigation Actions in Tanzania: assessing the concept's cultural legitimacy among stakeholders in the solar energy sector, 2016, Local Environment: the International Journal of Justice and Sustainability, 1-20.

Local Environment: the International Journal of Justice and Sustainability is available online at informaworldTM:

http://dx.doi.org/10.1080/13549839.2016.1161607

Copyright: Taylor \& Francis (Routledge): STM, Behavioural Science and Public Health Titles http://www.routledge.com/

Postprint available at: Linköping University Electronic Press http://urn.kb.se/resolve?urn=urn:nbn:se:liu:diva-126668 


\section{The transformational potential of Nationally Appropriate Mitigation Actions in Tanzania: assessing the concept's cultural legitimacy among stakeholders in the solar energy sector}

Latif Amars", a, b, Mathias Fridahl ${ }^{\mathrm{a}}$, Markus Hagemann ${ }^{\mathrm{c}, ~ d}$, Frauke Röser ${ }^{\mathrm{e}}$ and Björn-Ola Linnér ${ }^{\mathrm{a}}$

${ }^{a}$ Centre for Climate Science and Policy Research, Department of Thematic Studies Environmental Change, Linköping University, Linköping, Sweden, ${ }^{b}$ Independent climate researcher in Dar es Salaam, Tanzania; ${ }^{c}$ NewClimate Institute for Climate Policy and Global Sustainability, Cologne, Germany; ${ }^{d}$ Utrecht University, Faculty of Geosciences, Utrecht, Netherlands; ${ }^{e}$ NewClimate Institute for Climate Policy and Global Sustainability, Berlin, Germany.

*Corresponding author. Email: latifamars@gmail.com 


\title{
The transformational potential of Nationally Appropriate Mitigation Actions in Tanzania: assessing the concept's cultural legitimacy among stakeholders in the solar energy sector
}

\begin{abstract}
While energy-sector emissions remain the biggest source of climate change, many least-developed countries still invest in fossil-fuel development paths. These countries generally have high levels of fossil-fuel technology lock-in and low capacities to change, making the shift to sustainable energy difficult. Tanzania, a telling example, is projected to triple fossil-fuel power production in the next decade. This article assesses the potential to use internationally supported Nationally Appropriate Mitigation Actions (NAMAs) to develop solar energy in Tanzania and contribute to transformational change of the electricity supply system. By assessing the cultural legitimacy of NAMAs among key stakeholders in the solar energy sector, we analyse the conditions for successful uptake of the concept in (1) national political thought and institutional frameworks and (2) the solar energy niche. Interview data are analysed from a multi-level perspective on transition, focusing on its cultural dimension. Several framings undermining legitimacy are articulated, such as attaching low-actor credibility to responsible agencies and the concept's poor fit with political priorities. Actors that discern opportunities for NAMAs could, however, draw on a framing of high commensurability between experienced social needs and opportunities to use NAMAs to address them through climate-compatible development. This legitimises NAMAs and could challenge opposing framings.
\end{abstract}

Keywords: transformational change, sustainability, NAMAs, Tanzania, solar power, MLP 


\section{Introduction}

From a global perspective, low-carbon development is a prerequisite for meeting the dual goals of economic development and preventing dangerous interference with the climate system (GCEC 2014, UNEP 2014). Although the UN Framework Convention on Climate Change (UNFCCC) is clear that the main responsibility to mitigate climate change lies with developed countries, meeting global climate goals also requires substantial contributions by developing countries (UN 1992, IPCC 2014, UNFCCC 2015b). Therefore, the international community has developed several mechanisms to help developing countries meet development priorities while reducing emissions.

One such arrangement, Nationally Appropriate Mitigation Actions (NAMAs), is of particular interest for its potential to foster transformational change (Mersmann et al. 2014). Developing countries also generally favour NAMAs given their design flexibility, emphasis on development objectives, and national ownership (Morel and Delbosc 2012). However, the potential for NAMAs to contribute to transformational change is generally understudied, particularly when it comes to applying NAMAs in least-developed countries (LDCs).

For LDCs in particular, although not exclusively, NAMAs are generally not proposed for reducing current emissions, instead being treated as a means to avoid future developmentrelated emissions. NAMAs could provide significant impetus for transformational management favouring low-carbon development in LDCs. In most such countries, fossil-fueldependent sociotechnical systems are currently only starting to evolve, creating opportunities to avoid high-carbon development paths (Berkhout et al. 2011, Román and Hoffmaister 2012). Despite large sources of renewable energy, Tanzania is a good example of an LDC with low current emissions that projects drastic increases in the near future (cf. Figure 1).

Transformational change requires a favourable business, regulatory, and cultural environment for the uptake of renewables. Although all three dimensions are key factors for 
transformation, the cultural dimension has proven particularly important in the early phases of introducing innovative technologies or ideas (Geels and Verhees 2011), including renewables in the African context (Okafor and Joe-Uzuegbu 2010).

This article assesses the potential of internationally supported NAMAs to promote the transition towards low-carbon electricity supply systems in Tanzania by assessing the cultural legitimacy of the concept among key actors in the solar energy sector. NAMAs have been identified as particularly suited to supporting niche development that can help transform fossil-fuel-dependent electricity supply systems. A key factor in realising this potential is the level of legitimacy, defined as a generalised perception that NAMAs are desirable within the socially constructed system of norms, values, and regulation in Tanzania (cf. Suchman 1995, Geels and Verhees 2011). By assessing this cultural legitimacy, we analyse the conditions for successful uptake of the NAMA concept in 1) national political thought and institutional frameworks and 2) the solar energy technological niche in Tanzania.

The article is divided into six sections. Section two situates Tanzanian solar energy production within the wider electricity supply system and provides background to the NAMA concept. Section three outlines the data collection method and how the multi-level perspective (MLP) framework can be used to study cultural legitimacy. Section four presents the main results, which are subsequently discussed in section five using MLP to assess the cultural legitimacy of NAMAs and their potential to promote transformational change of the Tanzanian sociotechnical electricity supply system. Several factors that limit the cultural legitimacy of the concept are identified. These undermine its potential to be incorporated into national political thought and the solar energy niche and to contribute successfully to the lowcarbon transition. These obstacles require political attention and have implications for NAMA design that merit consideration if the concept is to be used as an instrument to manage transformation. Section six highlights the main conclusions of the article. 


\section{Tanzanian electricity supply and the NAMA concept}

\section{Tanzanian electricity production}

Both grid and off-grid electricity in Tanzania is generated primarily by two means: fossil fuel thermal power plants and hydropower (Figure 1).

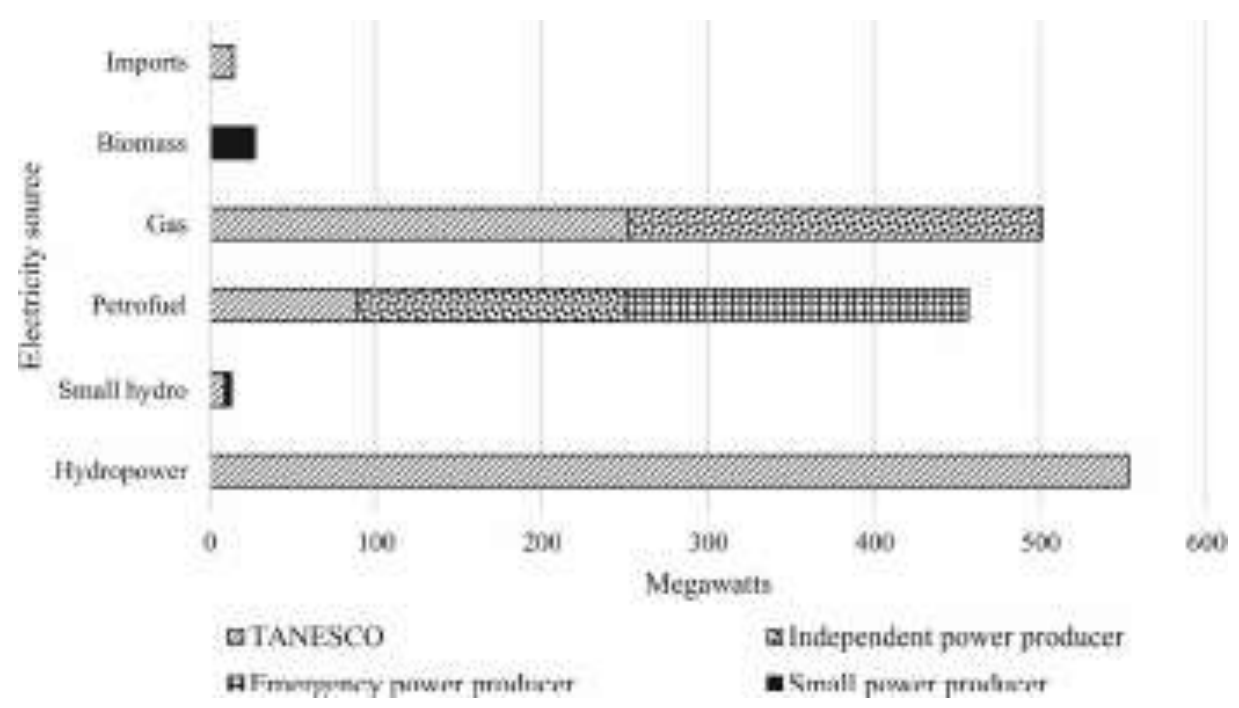

Figure 1. Electricity generation capacity in Tanzania, March 2013. Data: Ministry of Energy and Minerals (2013a).

Despite extensive sources of renewable energy such as geothermal, solar, wind, and hydro, fossil fuels are increasingly used to satisfy surging electricity demand (Ministry of Energy and Minerals 2013b). Tanzania aspires to become a middle-income country by 2025 . According to the government's Power System Master Plan 2012 Update, the increasing electricity demand associated with these development aspirations will be met primarily by hydropower, natural gas, and coal (Figure 2). 


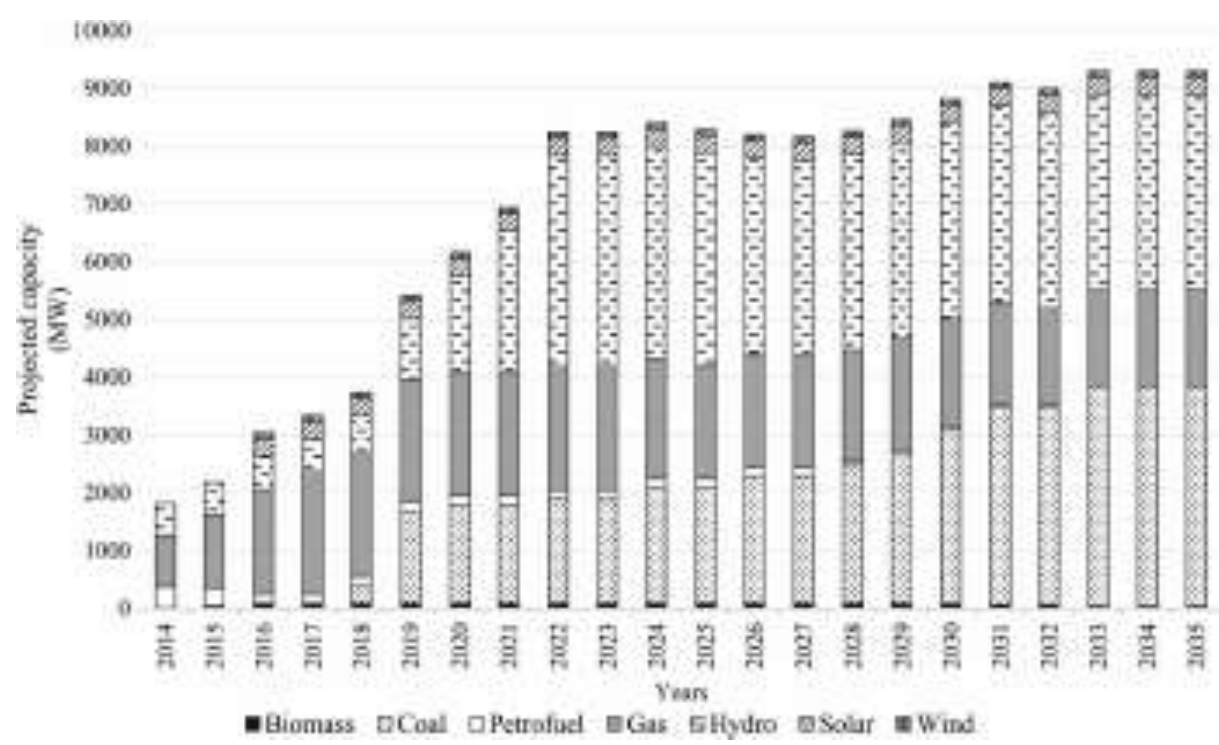

Figure 2. Projected electricity generation in Tanzania, 2014-2035. Data: Power System Master Plan 2012 Update (Ministry of Energy and Minerals 2013a). Note that the Master Plan does not factor in changed preconditions due to effects of climate change (which will likely affect hydropower negatively) or the Tanzanian programme to scale up renewable electricity generation.

Tanzania struggles with enormous energy poverty challenges, not least access to electricity. Although electricity production has increased in recent years, a staggering $98 \%$ of rural households (roughly $70 \%$ of the population is rural) had no access to electricity in 2011 , with daily electricity consumption being only approximately $91 \mathrm{kWh}$ per capita. If looking to the whole population (rural and urban), the World Bank reports that roughly 15\% of Tanzanians had access to electricity in 2013 (Camco Energy 2012, Gaddis et al. 2012, World Bank 2015). In addressing the parliament on the budget for 2015/16, a speech delivered in June 2015 by the Tanzanian minister of finance, Saada Mkuya Salum, more updated figures were provided indicating that access to energy, especially in rural parts of Tanzania, has increased dramatically in the last 5 years (Salum 2015). Although different estimates vary - the numbers are uncertain - it remains a fact that compared to the rest of the world, energy access in Tanzania is relatively low (see Table 1).

Photovoltaic (PV) technologies have been at the centre of government and donor programmes to increase access to electricity in Tanzania. Private sector investment in PV has also grown significantly in recent years. Low incomes, decentralised communities, and the 
flexibility of PV solutions have made PV the quintessential choice for many in rural

Tanzania. The cumulative capacity of PV installed in Tanzania grew from 100 kilowatts in 2010 to 5 megawatts in 2012 (Meza 2013). The capacity is still too small to be noticeable in overall statistics, yet the niche as well as interest in the technology continues to grow.

Table 1. Comparing key indicators of Tanzanian electricity generation and consumption with world average and countries at different stages of economic development.

\begin{tabular}{|c|c|c|c|c|c|c|c|c|c|}
\hline & \multirow{2}{*}{$\begin{array}{l}\text { Electric } \\
\text { power } \\
\text { consumption, } \\
2013 \\
{\text { [kWh/capita }]^{\mathrm{a}}}\end{array}$} & \multirow{2}{*}{$\begin{array}{l}\text { Access to } \\
\text { electricity, } \\
2012[\% \text { of } \\
\text { pop.] }{ }^{\text {b }}\end{array}$} & \multicolumn{7}{|c|}{ Electricity, net generation, $2012[\%]^{\mathrm{c}}$} \\
\hline & & & $\begin{array}{l}\text { T. } \\
0 \\
0 \\
0 .\end{array}$ & 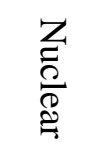 & 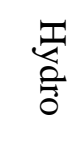 & 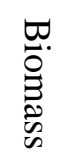 & $\sum_{\Xi}$ & 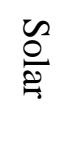 & 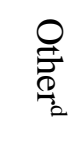 \\
\hline Tanzania & 91 & 15.3 & 69.8 & 0.0 & 29.6 & 0.3 & 0.0 & 0.2 & 0.0 \\
\hline China & 3766 & 100.0 & 62.3 & 1.9 & 29.8 & 0.9 & 2.0 & 0.1 & -0.1 \\
\hline Chile & 3865 & 99.6 & 62.3 & 0.0 & 29.8 & 7.3 & 0.6 & 0.0 & 0.0 \\
\hline India & 783 & 78.7 & 82.0 & 2.8 & 11.8 & 0.5 & 2.7 & 0.2 & 0.0 \\
\hline South Africa & 4328 & 85.4 & 94.2 & 5.2 & 0.8 & 0.1 & 0.0 & 0.0 & -0.4 \\
\hline The USA & 12987 & 100.0 & 68.6 & 19.0 & 6.8 & 1.8 & 3.5 & 0.1 & 0.3 \\
\hline World & 3026 & 84.6 & 67.3 & 10.9 & 16.9 & 1.8 & 2.4 & 0.4 & -0.1 \\
\hline
\end{tabular}

${ }^{a}$ IEA (2015) Key World Energy Statistics. Paris: International Energy Agency.

${ }^{\mathrm{b}}$ World Bank, Sustainable Energy for All (SE4ALL) database from World Bank, Global Electrification database.

${ }^{\mathrm{c}}$ US Energy Information Administration, International Energy Statistics database.

${ }^{\mathrm{d}}$ Includes geothermal and ocean energy and hydroelectric pumped. Other may sum to negative due to hydroelectric pumped.

\section{The institutional and regulatory framework for solar electricity production}

The framework underpinning the solar energy sector in Tanzania comprises a patchwork of legal instruments and institutions. The state-owned parastatal, Tanzania Electric Supply Company Limited (TANESCO), has a monopoly on electricity supply but has been plagued by inefficiencies and numerous major corruption scandals (Kabendera and Anderson 2014). Dependency on ageing hydropower plants has made TANESCO unable to meet growing demand, resulting in very common 12-hour power outages that worsen during the dry season 
when there is no enough water and demands for cooling also increase. To address the electricity shortage, TANESCO has resorted to diesel and natural gas generators. This strategy has made the electricity production price several times more expensive than the regulated price for customers, resulting in severe losses for the company (Bauner et al. 2012).

Besides increased electricity supply, enhanced grid access is a major challenge for most African countries (Bugaje 2006). In Tanzania, TANESCO's grid expansion has been slow. The Rural Energy Agency, established by the Electricity Act of 2008, promotes rural electrification through providing loans, grants, and other incentives for rural energy projects (IED 2014). In rural areas, generators running on expensive diesel account for most electricity production. In this context, PV is proposed as a low-cost alternative (Bertheau et al. 2014). Promoting PV has been a major instrumental strategy for the Agency, although measures such as promoting micro-hydro and energy efficiency have also been proposed (Ahlborg and Hammar 2014).

Energy sustainability underpins policies to promote green economic development and the achievement of poverty eradication goals in the National Strategy for Growth and Reduction of Poverty, Five-Year Development Plan, Vision 2025, and the acceleration framework for implementing the Millennium Development Goals. PV fits well with many of these strategies and goals, though it competes with policies promoting investment in natural gas and coal. Tanzania's general Energy Policy of 2003, currently under review, emphasises the need for the wider use of alternative energy and the efficient use of national energy sources. Notwithstanding this policy, practitioners in the solar energy sector discern a need for an independent policy that supports renewable energy development more effectively (Bauner et al. 2012). In this setting, NAMAs could be used to support both immediate interventions through projects and policy development more generally. 


\section{Political economy of low-carbon energy in Tanzania}

Analysis of the de jure institutions responsible with transition to sustainable energy regime alone is not enough. Power interplay within and outside the formal governance structures are equally important to determine the terms of the energy transition (Newell et al. 2014). Who makes the decisions and how accountable these decisions are has important ramifications for the energy transition in Tanzania. Solar is still largely dependent on government institutions and international donors for market and expertise (Ondraczek 2013). Donor funded government programs have played crucial role in the development of the entire value chain of the solar business in Tanzania. Donors, especially the development partners group are quite influential in the country, they have determined government priorities in many instances and continue to do so through material power-donor buy-in is essential for a successful interventions (Tilley 2014, Newell et al. 2014). Tanzania is one of the biggest recipient of donor aid of which a large share is going to general budget support (DPG 2015). In some instances, donors have withheld disbursements of aid to push for specific reforms within the government. Moreover, 'mutual interests' and foreign policy imperatives pushing for certain reform agenda typifies areas where donor aid is channeled (Tilley 2014).

Corruption in the energy sector is another area where power is contested. Clientelism and rent seeking of the elite class, comprised of politicians, administrators and an economic elite, is blamed for the worsening corruption situation in the sector. 'Relational accountability' (e.g. informal norms and tacit power relations) as opposed to 'procedural accountability' (e.g. formal and contractual) is deeply entrenched, leading to a situation where a group of powerful people i.e. elite class, influence almost all major decisions. Emergency capacity energy projects, mostly using fossil fuels, have been used as a tool by the elite class to line their deep pockets with taxpayers money (Cooksey 2002, Tilley 2014). Some have suggested that the involvement of the elite class in the renewable energy sector is the breakthrough needed to 
radically increase renewable energy adoption (Newell et al. 2014). However, as we shall see later, competitiveness and deeper involvement of the private sector critical for the growth of solar and renewable energy sector is now slowly growing; tax exemption of solar products and lobbying for reviewed feed-in tariff scheme are attributed to their participation thus establishing them as important actors.

\section{Nationally Appropriate Mitigation Actions (NAMAs)}

The NAMA concept was established by the UNFCCC in 2007, defined as "Nationally appropriate mitigation actions by developing country Parties in the context of sustainable development, supported and enabled by technology, financing and capacity building, in a measurable, reportable and verifiable manner" (UNFCCC 2008, p. 3).

Although the concept of NAMAs is relatively new, dedicated funding sources are already starting to become notable. The absence of a precise definition of NAMAs, however, has led to ambiguity as to how NAMAs should be formulated and implemented (BAPPENAS and GIZ 2012). International support institutions such as the KfW, NAMA Facility, Green Climate Fund, and World Bank are putting forward their own frameworks for evaluating the transformational change potential of NAMAs to foster the emergence of low-carbon societies (Fridahl et al. 2015, Winkler and Dubash 2015). NAMAs could facilitate the growth of the solar energy sector in Tanzania. It is acknowledged that the transformative potential of NAMAs is generally significant, as they can support the design and implementation of a broad range of actions, including projects, policies, and strategies to, for example, raise awareness, transfer technology and know-how, and address barriers to market entry for private investors. Furthermore, NAMAs provide opportunities to strengthen a low-carbon institutional framework and to supply resources to boost the development of the solar sector (Mersmann et al. 2014, Tilburg and Bhasin 2014, Fridahl and Linnér 2015). 
The willingness to make proposals explicitly labelled NAMAs, seeking to attract funding earmarked for the concept, is a key first determinant of the concept's potential to contribute to transformational change. According to the MLP on transformational change, this willingness would be significantly influenced by the level of cultural legitimacy attached to the NAMA concept.

\section{Multi-level perspective framework: conception of transformational change}

\section{favouring low-carbon development}

Technological innovations are not mere artefacts but rather are situated within the context of particular sociotechnical systems (Geels 2002). These systems are often conservative and lead to path dependency, i.e. systems that favour one specific innovation path over others (Hogarth 2012). Fischer-Kowalski and Rotmans (2009) contend that developing countries are trying to emulate developed countries' fossil-fuel-dependent and unsustainable industrial structures.

To overcome technological innovation lock-in, mere technical fixes are not enough; instead, transformational change is required (Bolton and Foxon 2015). This requires transitions of whole sociotechnical systems, transitions that "not only entail new technologies, but also changes in markets, user practices, policy and cultural meanings" (Geels 2010). The ability of NAMAs to foster such change is regarded here as its transformational potential. The present results are discussed in the context of the MLP framework in order to analyse the building blocks and conception of transformational change favouring low-carbon development.

MLP features three levels of sociotechnical system analysis, i.e. the niche, regime, and landscape levels (Geels and Schot 2007). Niche innovations are technical novelties that can lead to radical, disruptive innovation. These niches can grow from within prevailing sociotechnical regimes or can result from external influences, such as global market forces, climate change, and international politics (Geels and Schot 2007). Sociotechnical regimes 
involve "artefacts, knowledge, capital, labour, cultural meaning, etc.” (Geels 2004) that stabilise the technological development trajectories. Established technologies and their organisation in regimes cannot be replaced without changing other parts of the sociotechnical system as well (Hogarth 2012). A sociotechnical landscape "is an external structure or context for interactions of actors" (Geels 2002). The landscape pressure favours certain actions while discouraging others.

The interaction of processes between these three levels can result in the transformation of the sociotechnical system. As visualised in

\section{Increasing structuration \\ of activities in local practices}

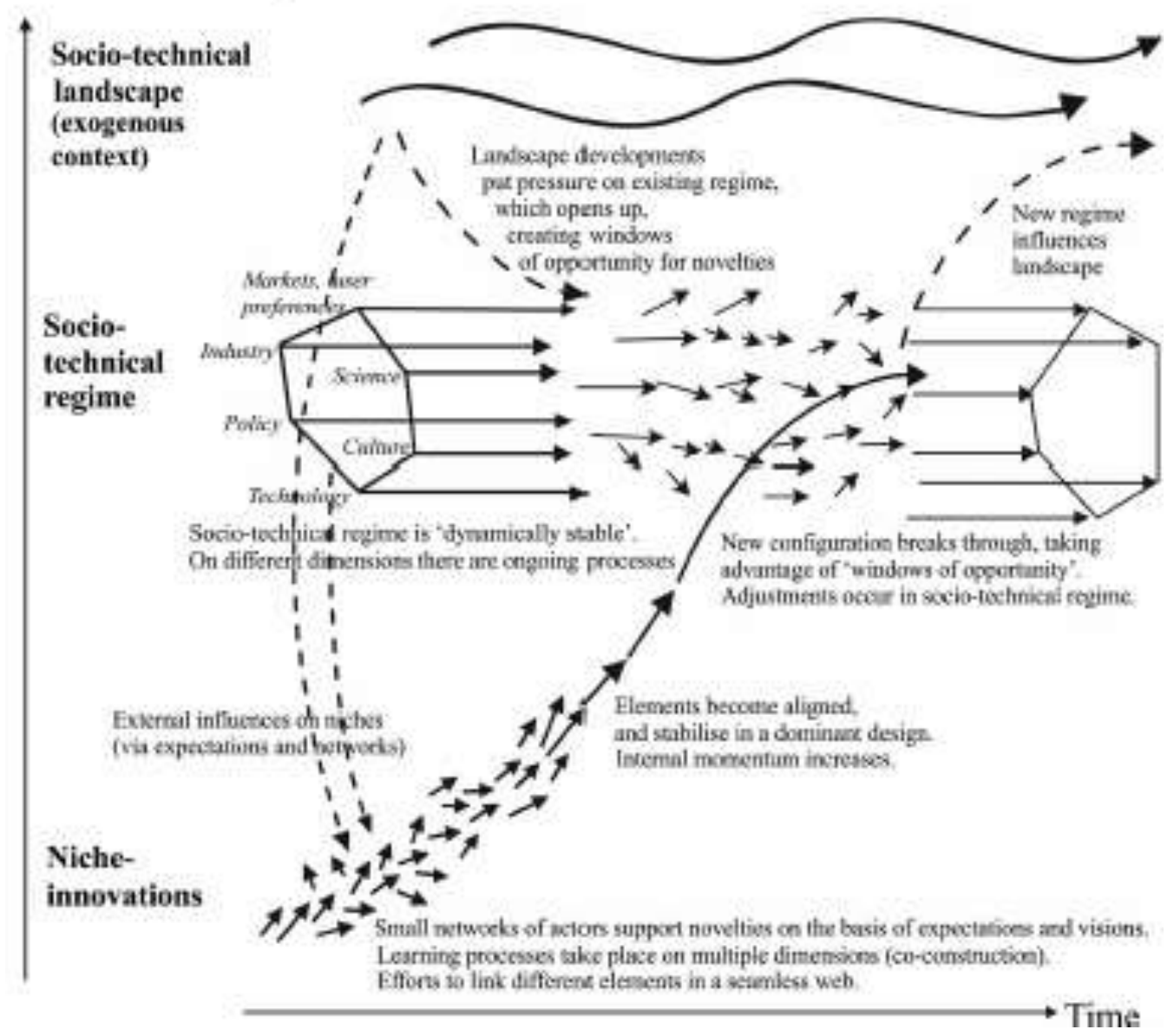

Figure 3, sociotechnical landscapes create bounded rationalities of individuals that result in nonlinear transformation punctuated by co-evolutionary processes (Geels 2002). 
Increasing structuration

of activities in local practices

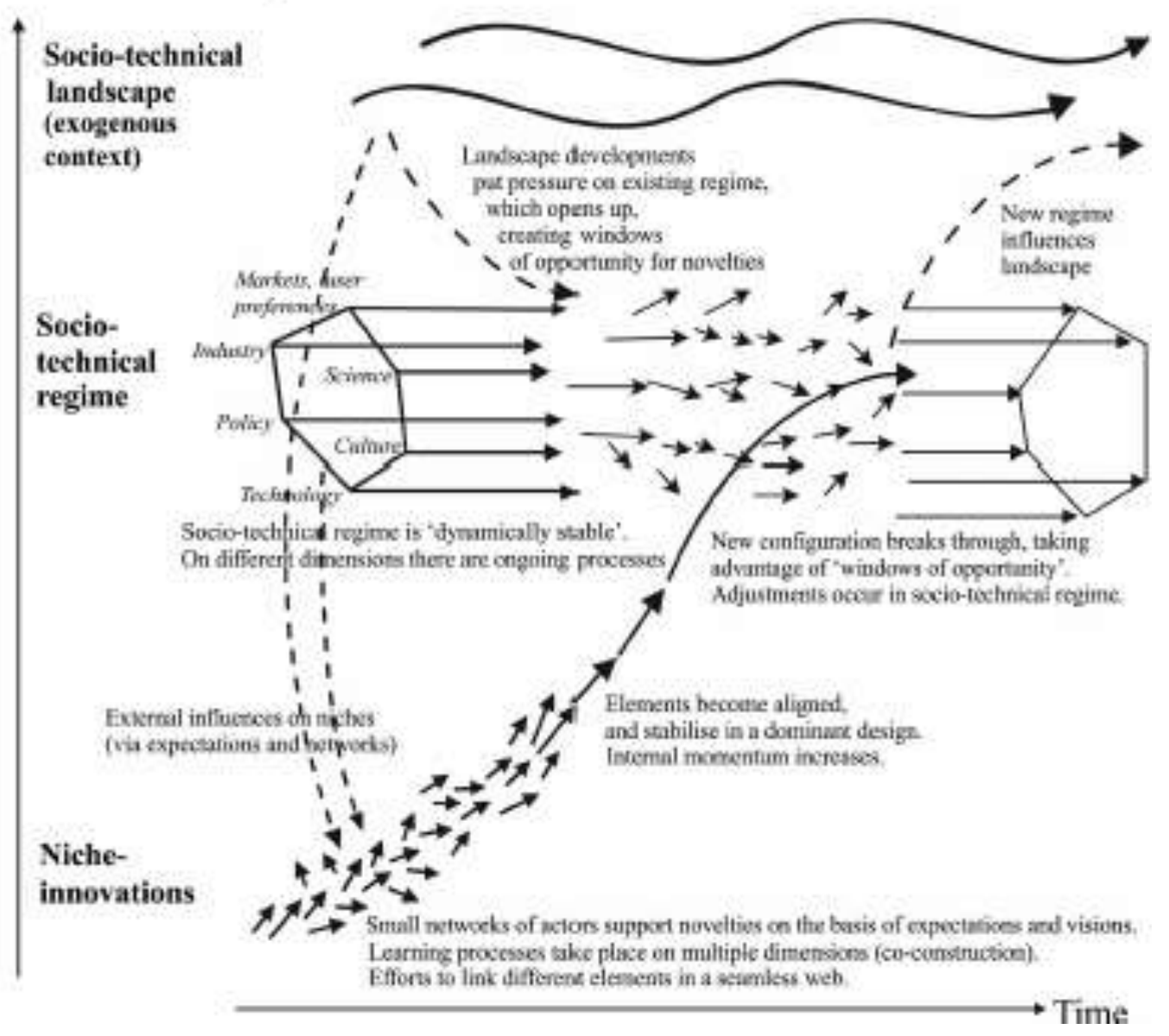

Figure 3. Multi-level perspective on transitions. Reprinted from Geels and Schot (2007) with permission from Elsevier.

The three levels should not be understood as ontologically representing transformation, but as analytical concepts with which to understand the complex processes of transition (Geels 2002, Geels and Schot 2007).

In this study, the NAMA concept is viewed as an exogenous concept introduced into the landscape by international politics, i.e. as an "outside pressure" (Mersmann et al. 2014) for change. Second, the solar sector is considered a niche. Niche development is a welldocumented factor favouring the transformational change of regimes (Smith and Raven 2012). The potential of the solar sector to help transform Tanzania's (macro) electric power 
system can be realised through providing conducive incentives for niche development, incentives to which NAMAs could contribute. However, when discursive repertoires at the landscape level and niche development go hand in hand, transformational regime change is much more likely to occur (Geels 2011).

Despite the significance of the cultural legitimacy of innovative technologies and of politics for transformational change, this dimension of transformation is rarely studied (Blum et al. 2015). The literature on MLP, however, offers a model for understanding framing struggles over legitimacy among actors engaged in niche development and in the more conservative regime (Garud et al. 2014, Geels and Verhees 2011). The success of framings in generating or undermining legitimacy has been demonstrated to hinge on: 1) the fit between the framing and the discursive repertoire at the landscape level, called "macro-cultural resonance"; 2) the perceived relative importance of the topic vis-à-vis other priorities, called "centrality"; 3) the social capital of the actors articulating a framing, called "actor credibility"; 4) the fit with empirical reality, such as the regulatory regime and technical system, called "empirical fit"; and 5) the resonance of the framing with everyday experiences such as the understanding of social needs, called "experiential commensurability" (Geels and Verhees 2011).

Here, we use this analytical schema in investigating the cultural legitimacy of NAMAs, to assess their transformative potential for the Tanzanian electricity supply system. We focus on the potential of NAMAs to help the solar sector induce change in the regime.

\section{Data collection}

To explore whether and how NAMAs can be incorporated into the landscape level of Tanzanian energy politics and practices and be used to support the solar energy technological niche, we conducted 15 semi-structured interviews (30-60 minutes) in person with policymakers and solar energy practitioners in Tanzania, 12-27 March 2014. The informants 
worked in various capacities for government ministries and agencies, bilateral donor agencies, non-governmental organisations, the private sector (e.g. as clean energy consultants), and social enterprise initiatives.

The interviews were recorded and transcribed verbatim. Phrases, sentences, and paragraphs were manually coded to identify themes in the transcripts corresponding to the five key elements of cultural legitimacy identified by Geels and Verhees (2011). The coding was conducted in an iterative process typically used for identifying themes in textual material (Strauss 1987, Corbin 2008). Documentary analysis of key strategies, policies, and laws supplemented information obtained through interviews. The analysis was particularly useful in contextualising the interviews and clarifying certain issues raised by the informants, and in understanding the regulatory framework in which NAMAs are situated.

\section{Results}

\section{Macro-cultural resonance and centrality: situating NAMAs within discourses of}

\section{Northern neo-colonialism}

Considering Tanzania's agrarian economy and small contribution to climate change, the government has prioritised adaptation over mitigation. At the same time, mitigation has greatly dominated donor-funded climate action in Tanzania, reflecting global priorities (Olsen 2006). According to Informant 12, most Tanzanians see climate change as a Northern problem. NAMAs are seen primarily as a mitigation rather than a development instrument, incapable of tackling development challenges that require prompt attention and immediately benefit the economy. NAMAs is therefore placed in a framing giving it low centrality, i.e. low importance in relation to other priorities. Despite the resemblance between the REDD and NAMA schemes, many informants situated NAMAs within a discourse of neo-colonialism (cf. Bachram 2004), framing it as a means to achieve mitigation rather than as an opportunity 
to support nationally defined sustainable development. This has led to perceptions that the concept is unsuitable for realising Tanzanian priorities.

Several informants maintain that NAMAs are not the right way forward. They see NAMAs as a way of shifting the burden of emission reduction to developing countries, despite developed countries' historical responsibility for climate change. Lending credence to the argument is the traditional development aid approach taken by some development partners that support NAMA activities, leading stakeholders to question the national appropriateness of NAMAs. Responding to the question of whether it is possible to have a nationally appropriate NAMA portfolio in Tanzania, Informant 9 explained: "Theoretically, it sounds like so. But practically and in real life, which we have been observing, it is not. ... It [i.e. NAMAs] is voluntary, you are saying, but later it becomes conditional". With experience of development aid, where certain prerequisites must be met for funding to be disbursed, the informants discern the potential for "NAMA hijacking" as opposed to "NAMA support" as a real threat. "NAMA hijacking", in the view of Informant 9, connotes a top-down approach in which donor concerns override national stakeholder priorities.

The informants, exemplified by a quotation from Informant 14 , also raised the concern that a balanced approach is required that ensures both bottom-up knowledge accumulation and top-down knowledge transfer: "We have to develop the programme together but when it comes top-down, people say this is a white man [project]. It's not ours!"

\section{Awareness and use of international support mechanisms for climate mitigation}

The informants also compare NAMAs to other international mechanisms that support climate action. Besides climate-related aid in general, two international support mechanisms defined by the UNFCCC are already in play in Tanzania: the Clean Development Mechanism (CDM) and Reducing Emissions from Deforestation and Forest Degradation (REDD). 
According to Informant 1, the CDM has failed in Tanzania: compared with neighbouring countries, Tanzania has struggled to capitalise on the CDM. This view is confirmed by statistics: Tanzania has secured only three projects (of more than 7600) and one programme of activities in the CDM. An additional seven projects have been rejected or withdrawn and two are currently in the validation phase (UNFCCC 2015a). According to the informants, experience and awareness of the CDM is low and it remains to be seen whether NAMAs will prove more successful. Informant 3 recalled a preparatory NAMA workshop organised by the UN Industrial Development Organization in 2013: "Participants in the meeting said ... we are still starting to learn about CDM and here comes NAMAs". The informant further noted that "there is that big challenge of awareness and I can see the same challenge shifting to NAMAs", a perspective reiterated by several other informants. Informant 8 added that the low prices of certified emission reductions from the CDM and the uncertain future of the mechanism have dissuaded private sector interest. All informants have in one way or another expressed that the CDM process is long, complex, unclear, and tailored for large projects, which they view as unsuitable for the Tanzanian context. A lack of capacity to meet the design requirements, coupled with the absence of significant sustainable cobenefits accrued, appears to have discouraged many stakeholders.

REDD faced similar challenges but, compared with the CDM, has made significant strides within a very short time. A readiness plan was submitted by 2008 after which Norway committed USD 83 million for a five-year support period (Norad 2011). The funding was used to initiate several REDD pilot projects, which were expedited by the involvement of Tanzanian government and research institutions, NGOs, local communities, and the private sector. As an outcome, a standalone National REDD Strategy and Action Plan was adopted in 2010. Besides funding, two other factors were important for the uptake of REDD: 1) the government saw REDD as an opportunity to meet its national obligations, including those of 
its Forest Act, to manage forests and reduce deforestation rates; and 2) it paralleled internationally supported initiatives such as National Forest Resources Monitoring and Assessment. REDD was framed as having a high empirical fit with the existing institutional and regulatory framework.

In fact, NAMA support has more in common with donor-driven REDD support than with the market-driven CDM. This means that Tanzania could be better equipped to attract NAMA finance than it was to attract CDM finance. While the CDM relies more on privatesector initiatives, NAMAs can be initiated by the government, spurred by outside pressure from proactive donors.

\section{Actor credibility: institutional ownership of NAMAs}

Although climate action has recently gained some traction, the informants maintained that poverty eradication and economic growth remain overriding priorities. Climate change has been placed under the authority of the Division of Environment (DoE) of the Vice President's Office, as it is still viewed primarily as an environmental issue and is driven by a donor focus on mitigation. Informant 2 observed that development partners had to come together and exert some pressure for climate change to be prioritised. However, considering that the DoE is seen as less influential and having less actor credibility than, for example, the Ministry of Finance (MoF) or the Ministry of Energy and Minerals (MEM), it has been difficult to rally political support to address climate change in the country.

Informants 2 and 13 added that the current institutional framework cannot adequately respond to the requirements for realising the potential of NAMAs and attributed slow progress to the limited capacity of the DoE. This lack of capacity has been dealt with by "outsourcing" climate change initiatives to even less influential non-governmental organisations and academics. 
This situation is starting to change, however. The Tanzanian government is working to set up a climate fund under the MoF to help attract international support for climate change adaptation and mitigation efforts. The informants regarded the more credible MoF as vital to helping Tanzania access climate finance, as the MoF has amassed substantial capacity in dealing with international support instruments. According to Informant 9, inadequate funding has delayed progress on NAMAs, arguing that "if you haven't got support for preparation, that means you'll move slowly". Without international support, the informant saw no reason why a poor country like Tanzania should not take the historical fossil fuel path.

Inferring from the interviews, there is agreement that the support available for climate change initiatives is inadequate and that this lack relates to low actor credibility and deficient capacity and authority of the responsible agency to budget for climate action. According to Informant 1, the Climate Change Strategy for Tanzania, developed by the DoE, lacks a detailed implementation plan and appropriate initiative costing, resulting in ad hoc mitigation initiatives that are unambitious and poorly coordinated.

\section{Empirical fit and experiential commensurability: perceived drivers of and barriers to solar energy growth}

PV programmes are undertaken against the backdrop of the unintegrated regulatory framework of governmental planning targeting the rural population and urban poor, as described above. Whether current interventions are meant to be temporary solutions while TANESCO strives to extend the national grid and improve electricity supply security is uncertain. Informants 3 and 5 observed that Tanzania has a limited budget and that grid extension to all households in this vast and sparsely populated country will be extremely costly, inefficient, and time consuming. The rural population, they argued, cannot wait 10-20 years for grid connection; efficient off-grid PV would meet the need immediately. 
According to many informants, surging electricity demand in unconnected rural areas is driving the rapid growth of the solar sector. Mitigation benefits are viewed as secondary. For example, when discussing incentives for solar energy, Informant 12 was quick to point out: "It doesn't have anything to do with climate change; it is driven by rural electrification and people wanting electricity".

Besides huge demand, the informants also identified other factors driving PV expansion. In particular, the involvement of private actors has helped establish a value chain for solar businesses. Several wholesale companies import solar products, mostly from China, transporting them to regional dealers who distribute them to small entrepreneurs who retail panels, batteries, and lights. However, several informants noted that the proliferation of lowquality products is negatively affecting the solar business. Most customers are located in poor rural areas. They use their hard-earned savings to buy these products, and when the products prove inferior, confidence in solar energy is eroded (Informants 8 and 5). Other informants noted that solar dealers also have to overcome difficulties related to distribution. Informant 5 described the challenge: "Getting it to every corner - and in a lot of places there are no tarmac roads ... the price goes up, which then reduces sales".

Several informants believed that government actions have benefited the solar sector and that there is clear interest in developing solar energy. Tax exemptions for solar products and equity contributions for rural entrepreneurs are among measures that continue to boost growth. In addition, the Rural Energy Agency has submitted a CDM programme of activities for renewable energy, which Informant 4 expected would benefit renewable energy producers and accelerate technology transfer.

According to the informants, NGOs and donors play a vital role in addressing market barriers and promoting overall support to the solar sector in Tanzania. They have been instrumental in subsidising solar products for the poor and training service providers, and 
have been big clients for local wholesalers of PV systems. Informant 5, on the other hand, asserted that funds from donor agencies have distorted both the PV market and the understanding of the true cost of doing business. Many economically unsustainable solar projects have consequently collapsed.

Although many informants had a negative view of donor driven- development, they also noted that aid finance has been instrumental in helping the private sector navigate the challenges of doing solar business in Tanzania.

\section{Perception of NAMAs in the context of social needs (experiential commensurability)}

The fact that the informants viewed PV interventions as arising from the necessity to provide electricity services to the people, regarding avoided emissions mostly as a co-benefit, has meant that solar sector NAMAs can gain traction among influential parts of the government. Although environmental concerns have been low on the agenda, if NAMA proposals focus on energy access rather than mitigation, they could become politically attractive. Some informants maintained that NAMAs could prove successful in contributing to transformational change by supporting the establishment of institutional arrangements and policies that could underpin a low-emission development strategy (e.g. Informant 13). They further stated that if additional resources could be leveraged through NAMAs, the implementation of existing sustainable development policies and plans could be accelerated (e.g. Informant 9).

Informants 4 and 9 argued that a portfolio of NAMAs could spur transformation only if the constituent NAMAs have positive impacts on the lives of millions living in economic and energy poverty. Since 2000, Tanzania has enjoyed impressive macroeconomic success. Still, over $90 \%$ of Tanzanians live on under two USD a day (Danish Ministry of Foreign Affairs 2013). The priority of the government is therefore on improving the lives of these Tanzanians, with improved energy access high on the priority list. 
Despite the growing deployment of solar energy technologies in Tanzania, awareness of solar energy remains low; similarly, there is little awareness of opportunities afforded by international climate mitigation mechanisms such as the CDM and NAMAs. Thus, according to Informant 11, there is a need to raise awareness of the mechanism itself and to build capacity to design specific solar NAMAs. Furthermore, according to several informants, knowledge transfer through NAMAs needs to deviate from the development aid approach in which experts "parachute" in and leave on completing the intervention. Expertise needs to be transferred to and retained in Tanzania (Informants 10 and 7).

Although policy NAMAs, as opposed to project NAMAs, can take a long time to yield significant results, they promise greater reach and thus have greater potential to spur transformation (Fridahl et al. 2015). However, the rural population of Tanzania favours immediate action to improve energy access. Government officials therefore face pressure to deliver tangible results that translate into experienced reality. According to most informants, an approach that combines new policy with more immediate projects is therefore preferred (cf. Informant 9).

\section{Discussion: the potential of NAMAs to contribute to transformational change of the Tanzanian electricity supply system}

According to Hogarth (2012, p. 259), "socio-technical transitions, such as a transition to a more climate-resilient and low-carbon economy, are impeded by an entrenched and selfreinforcing web of institutions, knowledge networks, cultural values and complementary infrastructures called a socio-technical regime". In Tanzania, both the electricity supply sociotechnical regime and its solar niche are in many respects at a nascent stage compared with the situation in other developing countries. Although the electricity supply system is growing, the great potential of solar energy is expected to remain largely untapped. The renewable share of total electricity production will likely remain low as the electricity supply 
system evolves to meet present and future electricity demand (cf. Figure 2) unless the niche and regime levels of the Tanzanian electricity supply system are deliberately managed towards transition.

\section{Assessing the cultural legitimacy of NAMAs}

Framings undermining legitimacy: negative articulations at the landscape and regime levels

Assessing the cultural legitimacy of NAMAs in Tanzania offers insights into how the MLP framework plays out in a country with few available resources to manage transitions, low R\&D investment, and underdeveloped governance structures, all of which are important factors for transition management (Kemp and Loorbach 2005). In this setting, the Tanzanian framing of NAMAs as an instrument of donor-driven, Northern neo-colonialism, drawing on macro-cultural discursive repertoires, undermines the concept's legitimacy. Negative framings of NAMAs that draw on landscape repertoires are not unique to Tanzania. Many actors in developing countries are sceptical of the NAMA mechanism, seeing it as a way to address environmental concerns and to make transformational change about reducing emissions rather than realising development (Winkler and Dubash 2015). That the actions understood as promoted by NAMAs were seen as having lower centrality than other priorities further undermines their legitimacy.

The fact that NAMAs are mostly framed as a mitigation instrument to achieve environmental objectives has led to responsibility for NAMAs being assigned to the DoE. Inferring from the informants, this actor is framed as having low influence and actor credibility, relative to other departments or ministries, still further undermining the legitimacy of NAMAs. Finally, the poor empirical fit of NAMAs with the regulatory framework 
undermines the concept's cultural legitimacy. This helps explain why NAMAs have not taken off in Tanzania.

These negative framings all operate at the landscape or regime level. When the informants drew on their experience of social needs and the benefits of PV, however, they generally framed NAMAs in more positive terms, highlighting opportunities and exploring drivers for overcoming several of the perceived problems with NAMAs articulated in the more negative framings. Although the solutions were discussed at the regime level, the positive framing arose from the informants' experience of the solar niche and the potential role of NAMAs.

\section{Framings underpinning legitimacy: opportunities in the solar energy niche}

In Tanzania, the explosive growth of the PV niche arose from the need to increase access to electricity and coincided with the decreasing cost of PV on the international market. The PV niche meets a special type of demand, i.e. a cost-effective means to produce electricity for poor rural households without grid access (Bertheau et al. 2014, Ahlborg and Hammar 2014). Although the informants articulated several framings relating to the landscape and regime levels that undermine the concept's cultural legitimacy, when speaking in more practical than conceptual or political terms, they were more positive regarding the potential of NAMAs to develop the solar niche. The need to reduce energy poverty among the rural poor, the practical and economic benefits of doing so using PV, and the eligibility criteria for accessing NAMA funding go hand in hand. This opens a way to build cultural legitimacy by underscoring the framings that illustrate how NAMAs can be tailored to be commensurate with the experienced need for rural social development. 
Table 2. Summary of framings, in terms of the five dimensions of cultural legitimacy that undermine or bolster the legitimacy of the NAMA concept.

\begin{tabular}{|l|l|l|}
\hline & $\begin{array}{l}\text { Framing that undermines } \\
\text { legitimacy }\end{array}$ & $\begin{array}{l}\text { Framing that underpins } \\
\text { legitimacy }\end{array}$ \\
\hline Macro-cultural resonance & - & \\
\hline Centrality & - & \\
\hline Actor credibility & - & \\
\hline Empirical fit & - & + \\
\hline $\begin{array}{l}\text { Experiential } \\
\text { commensurability }\end{array}$ & & \\
\hline
\end{tabular}

\section{The scope for successful uptake of NAMAs at the regime and niche levels}

The sociotechnical regime provides direction and incentives for a particular kind of innovation that, through the selection and retention process, leads to stabilisation of the regime (Geels 2002, Fischer-Kowalski and Rotmans 2009). Stabilisation is manifested, for example, by investment lock-in, routine behaviour, regulations and standards, everyday habits, and competencies concerning the technical system (Geels and Schot 2007).

Sociotechnical regimes create an environment in which the efficiency and affordability of the selected niche gradually improves and only incremental as opposed to transformational innovations are encouraged (Kemp and Loorbach 2005, van den Bergh et al. 2011).

Reflecting on the PV situation in Tanzania, the informants viewed the policy framework for developing the sector as unorganised and counterproductive. On the one hand, the government claims to favour off-grid connection through alternative energy sources, including PV; on the other hand, it undermines this ambition by subsidising fossil fuel energy production, making solar and other renewables uncompetitive. The development of renewable energy faces competition from the recent discovery of natural gas reserves off the southern coast of Tanzania. It is speculated that the East Africa offshore natural gas reserves, stretching from Kenya via Tanzania to Mozambique, are larger than the reserves of Nigeria, Africa's 
leading energy producer (Bariyo 2014). Tanzania has already developed a natural gas policy and, supported by big international companies, is setting up the infrastructure needed for domestic use and export. In contrast, the report of the Tanzanian Scaling Up Renewable Energy Programme states that "total estimated 2025 electricity demand of 27,000 GWh could be met by PV systems covering 15,000 hectares or about 0.02 percent of Tanzania's land mass" (Ministry of Energy and Minerals 2013b). This report aroused little government enthusiasm in the face of burgeoning gas reserves, which can be interpreted as a sign of the energy regime's conservative dynamics.

Given the low cultural legitimacy of NAMAs in Tanzania, it will be difficult to challenge the conservative dynamics of the energy regime and successfully use NAMAs to spur transformation. Adding to this situation, many informants (mostly those active at the regime level) thought that PV did not produce "real" electricity. This perception could be a result of how solar programmes are implemented in Tanzania, as most deployed systems are small solar home systems, micro-PV farms, and pico-PV systems. Parallel to this are concerns than NAMAs are an instrument of neo-colonial exploitation, and to some officials, sustainable energy has become synonymous with restricted energy (cf. Driessen 2010). These sentiments are conceptually congruent with Moss's (2012) analogy of the US sending low-calorie food aid to a famine-stricken country in response to the global obesity epidemic. Such actions will be ineffective at actually tackling the real problems. Over-dependence of the solar sector on donor finance coupled with the country's long history of failed donor programmes led the informants to question whether PV or other renewable energy technologies should be a priority for Tanzania. Transformation of the sociotechnical regime is influenced by these perceptions. National appropriateness of solar or renewable energy NAMAs will be an important consideration. In the event of NAMAs being put to use in Tanzania, it is vital to avoid a situation in which key stakeholders also experience what they describe as "NAMA 
hijacking". Obtaining proof of the real risks of such fears would only strengthen the framing that views NAMAs as an instrument in service of neo-colonial oppression.

Stressing the more positive experiential commensurability framing of NAMAs could be used to challenge the negative framings of NAMAs. According to the MLP framework, it would be wise to start by challenging the negative framing that draws on discursive landscape repertoires as this, combined with positive examples and niche-level development, would promote energy regime change from the landscape and niche levels. Changes at the landscape level admittedly take a long time. However, stakeholders in the electricity sociotechnical regime need to feel pressure exerted by the landscape level if they are to deviate from business as usual and allow innovative niches to flourish (Hodson and Marvin 2010). It is not viable to believe that the positive framing of high commensurability between NAMAs and experienced social needs can change the relatively stable discourses at the landscape level. However, the positive framing can be used to challenge the tendency to situate NAMAs within this discourse, or at least to carve out a discursive position for NAMAs that positions it as an innovative support mechanism that breaks with traditional aid by being qualitatively different in focus.

Technology niches also need to be sufficiently developed to take advantage of the opportunities created by positive landscape pressure (Geels and Schot 2007). NAMAs are framed by Tanzanian actors as primarily aiming to curb increasing emissions and, thus, to mitigate climate change. As suggested in previous studies of similar cases, if NAMA interventions emphasise mitigation potential rather than the support of rural development and the reduction of energy poverty, an opportunity to rally international support for renewable energy might be missed (Kaygusuz 2012). As long as NAMAs are framed as a mitigation mechanism, their cultural legitimacy will likely remain low. This will make it more difficult to realise the opportunities to design, for example, a policy NAMA in support of a more 
coherent regulatory framework - as requested by the informants. A few examples perceived as positive by key stakeholders might prove enough to bolster the existing positive framing by emphasising an empirical fit, i.e. providing practical examples of how NAMAs have been successfully used to address prioritised development needs.

After legitimacy: further research into the scope for NAMAs in the Tanzanian solar sector is required

If the cultural legitimacy of NAMAs can be increased so that the concept gains traction in Tanzania, the informants would be open to several potential uses of NAMAs. To influence the sociotechnical regime, long-term thinking needs to be the framework for short-term policy (Kemp and Loorbach 2005). Despite the large renewable energy sources as well as several strategies and programmes (see the section "Tanzanian electricity production"), there is no specific low-carbon development policy for implementing a vision emphasising solar and other renewables.

According to the informants involved in niche development, the best way to start the transition towards a low-carbon configuration of the electricity supply system would be to enact a policy promoting solar power in particular and renewables in general. Depending on their type, some NAMAs will likely have greater potential to realise transformational change than others. Categorising NAMAs into policy, strategy, and project types, Hänse et al. (2013, p. 15) comment: "Policies and strategies have a broader scope than projects, often in terms of both geography and time, and are likely to include longer-term objectives leading to transformational impacts". NAMAs with a broader scope would be desirable to give impetus to the solar and renewable energy niches. Well-designed policy interventions are also said to be among the best ways to spur low-carbon development in the energy sector in developing countries (Oyedepo 2012). 
Policy NAMAs, given their potentially economy- or sector-wide reach and large effects, are also the type of NAMA most favoured by support providers (Fridahl et al. 2015, Hänse et al. 2013). Resources added through NAMAs could, for example, be directed towards addressing barriers to private investment or funding renewable energy feed-in tariffs, subsidies, tax exemptions, technician training, etc. NAMA funders, however, also must be convinced to enter into long-term financial commitments, which they have generally been reluctant to do (Fridahl et al. 2015).

Awareness, knowledge transfer, and capacity building are also, according to the informants, essential areas to boost the development of the niche that could be addressed by NAMAs (Kaygusuz 2012). Very little solar energy R\&D is undertaken in Tanzania. A scarcity of funding and support structure makes it difficult for the disparate actors to innovate, making them reliant on international R\&D. Consideration of how to overcome these deficiencies ought to be embodied in NAMAs addressing the niche.

PV is well adapted to the market-driven approaches in Tanzania and well suited to reaching those living in remote areas and at the bottom of the income pyramid, i.e. most rural Tanzanians (Ahlborg and Hammar 2014). PV systems are designed so that more components can be added over time. A buyer can first buy a small system and then slowly add more components depending on needs and purchasing power. This design aspect is significant given the prevalence of poverty in Tanzania's socioeconomic context. A study in Kenya, for example, demonstrated that large home solar systems are needed for households to realise economically productive uses, a factor that effectively confines these benefits to rural elites (Jacobson 2007). The study also reported that the primary motivation for most buyers is not income generation catalysed by the PV system but connective uses (e.g. for charging mobile phones or powering television and radio). In Tanzania, it would be wise to determine whether 
such drivers exist in the socioeconomic context; NAMA interventions should be targeted accordingly if they are to have a transformational effect.

The MLP framework should not be taken prescriptively, as not all niches succeed. The existence of multiple alternative arrangements forming a niche cluster increases the chance that one or more of these arrangements will challenge the entrenched regime (Berkhout et al. 2004). However, a Tanzanian strategy, based on applying a set of NAMAs to support the solar energy technological niche, for shifting the electricity supply system onto a low-carbon development trajectory is currently lacking. With an MLP approach, the design of a solar energy NAMA strategy, targeting several levels of the sociotechnical regime, can be used to create entry points for further investments in renewable energy and to provide more opportunities to challenge the prevailing sociotechnical regime. Based on the view of barriers to NAMAs in Tanzania articulated by the informants, such a strategy should contain components intended to secure support for bigger projects and programmes over longer timescales, supportive policy to incentivise private engagement, awareness and education campaigns to build capacity, and processes that ensure ownership of the projects. It is also crucial that the NAMA projects and programmes be designed to emphasise positive effects on the lives of poor people. Such a strategy could effectively spur transformation, leveraging support from NAMAs, but only if the Tanzania's regulatory framework and supporting institutions are drastically improved.

\section{Notes on the scope of this study}

It is worth recalling that this study is based on key regime- and niche-level stakeholders' perceptions of the Tanzanian solar energy sector. Although many of these actors are also involved in other sectors, especially those active at the regime level (e.g. government representatives and civil servants), the analysis is limited to assessing the cultural legitimacy of NAMAs in fostering transformational change of the sociotechnical electricity supply 
system by supporting the solar energy sector. As such, an assessment of the cultural legitimacy of NAMAs among stakeholders engaged primarily in other sectors, such as transport, waste, agriculture, and forestry, could yield different results.

It is also worth recalling that cultural legitimacy is particularly significant in early phases of innovation. An assessment of the cultural legitimacy of NAMAs can only speak to the question of indicative, ex ante effectiveness. Cultural legitimacy has been found to significantly influence the uptake and sustained support of innovative ideas, such as NAMAs, at the various levels of a sociotechnical system (cf. Geels and Verhees 2011). Real effectiveness, in terms of an integrated ex post evaluation of actual contributions to transformational change, can only occur if NAMAs first gain traction, are postulated, attract support, and are implemented. Part of such evaluations should focus on the cultural dimension of the sociotechnical system. Mapping the concept's cultural legitimacy and identifying opportunities for the concept to gain traction at all system levels is an important start. The next steps involve identifying and overcoming barriers in the business and regulatory dimensions of the system so that all dimensions work in concert to promote the much-needed low-carbon development.

\section{Conclusions}

The extent to which the transformative potential of the international support mechanism of Nationally Appropriate Mitigation Actions (NAMAs) for low-carbon development can be realised in national contexts is influenced by the concept's cultural legitimacy at several levels of sociotechnical energy systems. Interviews with key stakeholders in the development of the Tanzanian solar energy niche indicate that these actors generally describe NAMAs in terms of framings that undermine their cultural legitimacy. The informants 1) connect NAMAs to a macro-cultural discursive repertoire that frames the concept as a tool for northern neo-colonial oppression, 2) attach low influence to the government actors (low actor 
credibility) responsible for NAMAs, 3) frame NAMAs almost exclusively as a mitigation instrument, making them a much less central priority (low centrality) than other political issues in Tanzania, and 4) argue that the empirical fit between NAMAs and the regulatory framework is poor. All of these framings undermine the cultural legitimacy of NAMAs.

The low cultural legitimacy of NAMAs suggests that it will currently be difficult to realise the concept's transformational potential in the Tanzanian context. However, the informants do acknowledge that photovoltaic technology is a key to the efficient rural off-grid electrification required to meet the development needs of most Tanzanians living in poor rural areas and suffering from energy poverty. The framing of positive experiential commensurability between social needs and opportunities to use NAMAs somewhat counters the more negative framings and grants the concept some legitimacy. This framing could be exploited to boost the concept's cultural legitimacy. If this is followed by successfully implemented NAMAs in the solar sector that showcase how international climate finance can be tailored to address the social needs of the rural poor, this would provide a positive example of good empirical fit between the concept and material reality. This could challenge the macro-discursive repertoire that undermines the cultural legitimacy of NAMAs. If macrodiscourses at the landscape level go hand in hand with emphasising the opportunities to use NAMAs to foster niche development, the concept's potential to catalyse transformational change favouring a low-carbon configuration of the Tanzanian electricity supply system has a much greater chance of being realised.

\section{References}

Ahlborg, H. and Hammar, L. 2014. Drivers and barriers to rural electrification in Tanzania and Mozambique: grid-extension, off-grid, and renewable energy technologies. Renewable Energy, 61, 117-124.

Bachram, H. 2004. Climate fraud and carbon colonialism: the new trade in greenhouse gases. Capitalism Nature Socialism, 15(4), 5-20. 
BAPPENAS and GIZ, 2012. Background study: development of the Indonesian NAMA framework. Jakarta: Ministry of National Development Planning (BAPPENAS) and Deutsche Gesellschaft für Internationale Zusammenarbeit (GIZ).

Bariyo, N., 2014. Tanzania Looks to Review Gas and Mining Sector Agreements [online]. Available from: http://blogs.wsj.com/frontiers/2014/09/04/tanzania-looks-to-reviewgas-and-mining-sector-agreements/.

Bauner, D., et al., 2012. Sustainable Energy Markets in Tanzania. Report.

Berkhout, F., Smith, A. and Stirling, A., 2004. Socio-technological Regimes and Transition Contexts. In: Elzen, B., Geels, F. W. and Green, K. eds. System Innovation and the Transition to Sustainability: Theory, Evidence and Policy. Cheltenham and Northampton: Edward Elgar Publishing, 48-75.

Berkhout, F., Wieczorek, A. and Raven, R. P. J. M. 2011. Avoiding environmental convergence: a possible role for sustainability experiments in latecomer countries? International Journal of Institutions and Economics, 3(2), 367-385.

Bertheau, P., et al. 2014. Energy Storage Potential for Solar Based Hybridization of Off-grid Diesel Power Plants in Tanzania. Energy Procedia, 46, 287-293.

Blum, N. U., Bening, C. R. and Schmidt, T. S. 2015. An analysis of remote electric mini-grids in Laos using the Technological Innovation Systems approach. Technological Forecasting and Social Change, 95, 218-233.

Bolton, R. and Foxon, T. J. 2015. A socio-technical perspective on low carbon investment challenges: insights for UK energy policy. Environmental Innovation and Societal Transitions, 14, 165-181.

Bugaje, I. M. 2006. Renewable energy for sustainable development in Africa: a review. Renewable and Sustainable Energy Reviews, 10(6), 603-612.

Camco Energy, 2012. Camco and joint venture partner Rex Investment Ltd win competitive tender in Tanzania [online]. Dar es Salaam: Camco Clean Energy. Available from: http://www.camcocleanenergy.com/blog/camco-and-joint-venture-partner-rexinvestment-ltd-win-competitive-tender-in-tanzania [Accessed 06-January-2015].

Cooksey, B., 2002. The Power and the Vainglory: Anatomy of a \$100 Million Malaysian IPP in Tanzania. Ugly Malaysians?: South-South investments abused. Durban: Institute for Black Research.

Corbin, J. M., 2008. Basics of qualitative research: techniques and procedures for developing grounded theory. 3rd ed ed. Los Angeles, Calif: Sage Publications, Inc.

Danish Ministry of Foreign Affairs, 2013. Country Policy Paper: Tanzania. Dar es Salaam: Danish Embassy.

DPG, 2015. Budget Support in Tanzania 2014/2015. Development Partners' Budget Support Group.

Driessen, P., 2010. Eco-Imperialism: Green Power Black Death. First Edition edition ed. Bellevue, Wash: Merril Press.

Fischer-Kowalski, M. and Rotmans, J. 2009. Conceptualizing, Observing and Influencing Social-Ecological Transitions. Ecology \& Society, 14(2), art. 3.

Fridahl, M., et al. 2015. A comparison of design and support priorities of Nationally Appropriate Mitigation Actions (NAMAs). The Journal of Environment \& Development, 24(2), 237-264.

Fridahl, M. and Linnér, B.-O. 2015. Perspectives on the Green Climate Fund: Possible Compromises on Capitalization and Balanced Allocation. Climate and Development, (Online first, DOI: 10.1080/17565529.2015.1040368).

Gaddis, I., Morisset, J. and Wane, W., 2012. Only 14\% of Tanzanians have electricity: What can be done? [online]. Washington: The World Bank, Africa CAN. Available from: 
http://blogs.worldbank.org/africacan/only-14-of-tanzanians-have-electricity-what-canbe-done [Accessed 01-June-2015].

Garud, R., Schildt, H. A. and Lant, T. K. 2014. Entrepreneurial Storytelling, Future Expectations, and the Paradox of Legitimacy. Organization Science, 25(5), 14791492.

GCEC, 2014. Better Growth, Better Climate. The New Climate Economy Report. Washington: The Global Commission on the Economy and Climate.

Geels, F. W. 2002. Technological transitions as evolutionary reconfiguration processes: a multi-level perspective and a case-study. Research Policy, 31(8), 1257-1274.

Geels, F. W. 2004. From sectoral systems of innovation to socio-technical systems. Insights about dynamics and change from sociology and institutional theory. Research Policy, 33(6), 897-920.

Geels, F. W. 2010. Ontologies, socio-technical transitions (to sustainability), and the multilevel perspective. Research Policy, 39(4), 495-510.

Geels, F. W. 2011. The multi-level perspective on sustainability transitions: responses to seven criticisms. Environmental Innovation and Societal Transitions, 1, 24-40.

Geels, F. W. and Schot, J. 2007. Typology of sociotechnical transition pathways. Research Policy, 36(3), 399-417.

Geels, F. W. and Verhees, B. 2011. Cultural legitimacy and framing struggles in innovation journeys: a cultural-performative perspective and a case study of Dutch nuclear energy (1945-1986). Technological Forecasting \& Social Change, 78(6), 910-930.

Hänse, G., et al., 2013. Annual Status Report on Nationally Appropriate Mitigation Actions (NAMAs), 2013. Cologne, Germany: Mitigation Momentum.

Hodson, M. and Marvin, S. 2010. Can cities shape socio-technical transitions and how would we know if they were? Research Policy, 39(4), 477-485.

Hogarth, J. R. 2012. The role of climate finance in innovation systems. Journal of Sustainable Finance \& Investment, 2(3-4), 257-274.

IED, 2014. United Republic of Tanzania National Electrification Program Prospectus. Dar es Salaam, Tanzania: Innovation Energie Développement.

IPCC, 2014. Climate Change 2014: Mitigation of Climate Change. Contribution of Working Group III to the Fifth Assessment Report of the Intergovernmental Panel on Climate Change. Cambridge, United Kingdom and New York, NY, USA: Cambridge University Press.

Jacobson, A. 2007. Connective Power: Solar Electrification and Social Change in Kenya. World Development, 35(1), 144-162.

Kabendera, E. and Anderson, M., 2014. Tanzanian PM under pressure to resign over alleged fraudulent payments [online]. London: The Guardian. Available from:

http://www.theguardian.com/global-development/2014/nov/28/tanzania-primeminister-mizengo-pinda-alleged-fraudulent-payments-energy-contracts [Accessed 1001-2015].

Kaygusuz, K. 2012. Energy for sustainable development: a case of developing countries. Renewable and Sustainable Energy Reviews, 16, 1116-1126.

Kemp, R. and Loorbach, D., 2005. Dutch policies to manage the transition to sustainable energy. In: Beckenbach, F., et al. eds. Innovationen und Nachhaltigkeit: Jahrbuch Ökologische Ökonomik 4 [Innovation and Sustainability: Yearbook of Ecological Economics 4]. Marburg, Germany: Metropolis Verlag, 123-151.

Mersmann, F., et al., 2014. Understanding transformational change in NAMAs: From theory to practice. Berlin and Roskilde: Wuppertal Institute for Climate, Environment and Energy and UNEP DTU Partnership. 
Meza, E., 2013. Special Report Africa: Tanzania, Mozambique [online]. Berlin: pv magazine, Solarpraxis AG. Available from: http://www.pvmagazine.com/news/details/beitrag/special-report-africa--tanzania-mozambique_100013524/.

Ministry of Energy and Minerals, 2013a. Power System Master Plan: 2012 Update. Dar es Salaam: United Republic of Tanzania.

Ministry of Energy and Minerals, 2013b. Scaling Up Renewable Energy Programme (SREP): Investment Plan for Tanzania. Dar es Salaam: United Republic of Tanzania.

Morel, R. and Delbosc, A., 2012. Financing climate actions in developing countries: what role is there for NAMAs? Paris: CDC Climat.

Moss, T., 2012. Let Them Eat Solar Panels: The Hypocrisy of Western Greens on Energy Poverty [online]. Oakland, CA: Breakthrough Institute. Available from: http://thebreakthrough.org/index.php/programs/energy-and-climate/let-them-eat-solarpanels [Accessed 07-September-2014].

Newell, P., et al. 2014. The Political Economy of Low Carbon Energy in Kenya. IDS Working Papers, 2014(445), 1-38.

Norad, 2011. Real-time evaluation of Norway's International Climate and Forest Initiative contributions to national REDD+ processes 2007-2010: country report Tanzania. Oslo: Norwegian Agency for Development Cooperation (Norad).

Okafor, E. N. C. and Joe-Uzuegbu, C. K. A. 2010. Challenges to development of renewable energy for electric power sector in Nigeria. International Journal Of Academic Research, 2(2), 211-216.

Olsen, K. H. 2006. National ownership in the implementation of global climate policy in Uganda. Climate Policy, 5(6), 599-612.

Ondraczek, J. 2013. The sun rises in the east (of Africa): A comparison of the development and status of solar energy markets in Kenya and Tanzania. Energy Policy, 56, 407417.

Oyedepo, S. O. 2012. On energy for sustainable development in Nigeria. Renewable and Sustainable Energy Reviews, 16, 2583-2598.

Román, M. and Hoffmaister, J. P. 2012. Climate and development: the potential for climate co-benefits in the Mozambican rice sector. Climate and Development, 4(3), 219-233.

Salum, S. M., 2015. Hotuba ya mheshimiwa waziri wa fedha, Saada Mkuya Salum (MB.), Akiwasilisha Bungeni Mapendekezo ya serikali kuhusu makadirio ya mapato na matumizi kwa mwaka 2015/16 [^Budget address to parliament by minister of Finance, Saada Mkuya Salum, on government expenditure and revenue for 2015/16]. Dar es Salaam. Available from: http://www.mof.go.tz/mofdocs/budget/speech/HOTUBA\%20YA\%20WAZIRI\%20W A\%20FEDHA\%20-\%202015-16\%20FINAL.pdf [Accessed 18 January 2016].

Smith, A. and Raven, R. 2012. What is protective space? Reconsidering niches in transitions to sustainability. Research Policy, 41(6), 1025-1036.

Strauss, A. L., 1987. Qualitative Analysis for Social Scientists. New York: Cambridge University Press.

Suchman, M. C. 1995. Managing Legitimacy: Strategic and Institutional Approaches. Academy of Management Review, 20(3), 571-610.

Tilburg, X. V. and Bhasin, S., eds., 2014. Annual Status Report on Nationally Appropriate Mitigation Actions (NAMAs), 2014. Petten, The Netherlands and Cologne, Germany: ECN and Ecofys Germany.

Tilley, H., 2014. The political economy of aid and accountability : the rise and fall of budget support in Tanzania. [Elektronisk resurs]. Farnham, Surrey, England ; Burlington, Vermont : Ashgate, 2014. 
UN, 1992. The Framework Convention on Climate Change. A/AC.237/18 (Part II)/Add.1. United Nations.

UNEP, 2014. The Emissions Gap Report 2014: A UNEP Synthesis Report. Nairobi: UN Environment Programme.

UNFCCC, 2008. COP13: report (addendum 1), Bali 2007. FCCC/CP/2007/6/Add.1. Bonn, Germany: UN Framework Convention on Climate Change.

UNFCCC, 2015a. CDM Insights: intelligence about the CDM at the end of each month [online]. UNFCCC Secretariat. Available from: http://cdm.unfccc.int/Statistics/Public/index.html [Accessed 19-06-2015].

UNFCCC, 2015b. COP20 report (addendum 1), Lima 2014. FCCC/CP/2014/10/Add.1. Bonn, Germany: United Nations Framework Convention on Climate Change.

van den Bergh, J. C. J. M., Truffer, B. and Kallis, G. 2011. Environmental innovation and societal transitions: Introduction and overview. Environmental Innovation and Societal Transitions, 1(1), 1-23.

Winkler, H. and Dubash, N. K. 2015. Who determines transformational change in development and climate finance? Climate Policy, (Online first, DOI: 10.1080/14693062.2015.1033674), 1-9.

World Bank, 2015. World Bank Open Data [online]. Washington: World Bank Group. Available from: http://data.worldbank.org [Accessed 26-June-2015]. 